\title{
EDITORIAL
}

\section{Paediatric interstitial lung disease: not just kid's stuff}

\author{
A. Bush
}

Interstitial lung disease (ILD) may be a diagnostic conundrum and a therapeutic puzzle at all ages, but especially so in paediatric practice. First, because it is rare in children. The prevalence in the adult population was estimated in one study as $\sim 70$ per 100,000 [1], but the limited paediatric data in the literature would suggest it is at least two orders of magnitude less common in children. For example, a survey from the UK estimated the prevalence at 0.36 per 100,000 [2]. Even allowing for the likelihood of under-diagnosis and under-reporting, this is still a very rare group of conditions in children. Secondly, there is far greater diversity in the types of disease found in children. Newly described entities include pulmonary interstitial glycogenosis (PIG) [3], neuroendocrine cell hyperplasia of infancy (NEHI) [4] and the disorders of surfactant metabolism (discussed in detail below). Usual interstitial pneumonia (UIP), relatively common in adults, is very unusual indeed in children. Thirdly, paediatric ILD occurs in the context of normal lung development; indeed the majority are diagnosed in the first year of life [2, 5], at a time when rapid alveolar multiplication is taking place [6]. This combination of rarity, diversity and context has meant that much of what is known about paediatric ILD is merely anecdotal. Such studies as have been carried at involved small numbers of patients, with no randomised controlled trials to guide treatment. However, two important themes are emerging: the two-way cross-fertilisation of ideas between adult and paediatric pulmonologists; and the need for international collaboration. The European Respiratory Society (ERS) has an unrivalled track record in both areas, and now is the perfect opportunity to make headway in both adult and paediatric ILD.

The super-hot topic of surfactant metabolism perfectly illustrates the overlap between the apparently totally disparate fields of adult chronic ILD and the infant dying of intractable respiratory failure. Pulmonary alveolar proteinosis (PAP) is characterised histologically by alveoli that are filled with granular, eosinophilic material staining with periodic-acid Schiff with preservation of lung architecture. Initially, two forms were recognised: "idiopathic", responding very well to whole lung, large volume lavage; and "secondary" to conditions associated with functional impairment of the macrophage, such as haematological cancers and some infections [7-10]. The possible role of granulocyte macrophage colony stimulating factor (GM-CSF) in PAP was highlighted when the GM-CSF-knockout mouse was found to have a PAP-like illness with normal surfactant synthesis and with recovery after GM-CSF replacement [11, 12]. Subsequently, late-onset idiopathic PAP was found to be an autoimmune disease, with autoantibodies targeting GM-CSF $[13,14]$, or, rarely, with a defect in GM-CSF/interleukin

Correspondence: A. Bush, Dept of Paediatric Respiratory Medicine, Royal Brompton Hospital, Sydney Street, London SW3 6NP, UK. Fax: 44 2073518763. E-mail: a.bush@rbh.nthames.nhs.uk
(IL)-3/IL-5 receptor common $\beta$ chain [15]. It would appear that GM-CSF regulates surfactant homeostasis via CD36 peroxisome proliferator-activated receptor (PPAR)- $\gamma$ [16]. GM-CSF therapy in PAP restores PPAR- $\gamma$ levels to normal.

The scene then shifted to infantile PAP, in which term infants developed an illness similar to pre-term respiratory distress syndrome, but instead of recovering, progressed to terminal respiratory failure. Defects in the gene encoding surfactant protein (SP)-B were found to be associated with this congenital form of PAP. The SP-B gene is located on chromosome 2 , and consists of 11 exons and $9.5 \mathrm{~kb}$. The gene product is a pre-proSP-B, size $\sim 40 \mathrm{kDa}$, which is processed at both amino and carboxyterminal ends to produce mature SPB $(8 \mathrm{kDa})$. The complexities of SP-B metabolism have recently been reviewed [17]. A number of mutations have been described, the commonest being a frameshift mutation in exon 4 (1549C $\rightarrow$ GAA, 121ins2), but also 122delC [18], $457 \mathrm{delC}$ [19] and others [20]. The mutation frequency in the population is probably 1 per $1-3,000$ individuals [21]. The underlying metabolic defect has been characterised in detail [22]. The mutated gene is transcribed normally, but an unstable mRNA is produced. Typically, the disease presents as relentlessly progressive respiratory failure in a term baby, with radiographs showing ground glass shadowing or established fibrosis. Diagnosis is established by absence of SP-B staining of tracheal aspirates or lung biopsy. Reliance on tracheal aspirate alone may be misleading; transient absence of SP-B from aspirate, but not lung biopsy, has been described in an infant with a mutation in one SP-B gene, but with the second gene copy normal [23]. Diagnostic confusion may also be caused because SP-C is also misprocessed, but this is a secondary phenomenon [24]. The only known therapy is lung transplantation, which has been performed successfully in only a few infants [25], despite the development of antibodies against SP-B after transplantation.

However, SP-B deficiency is more than just infants dying tragically early. A recent report has broadened the spectrum of SP-B deficiency to a cause of ILD in older children. Two infants with respiratory failure, one surviving untransplanted for several years, were found to have immunostaining consistent with SP-B deficiency [26]. Both children were homozygous for an exon-5 splice-site mutation, which resulted in a frameshift and a premature termination codon in exon 7. However, Western blot determined the presence of reduced amounts of mature SP-B and an abnormal SP-B proprotein, presumed to be a result of skipping exon 7 , and resulting in a milder phenotype than the classical disease.

Subsequently, defects in SP-C have been found to be associated with both adult and paediatric ILD. The first cases were in a female with desquamative interstitial pneumonitis diagnosed at $1 \mathrm{yr}$, treated with corticosteroids until $15 \mathrm{yrs}$. Her infant also had nonspecific interstitial pneumonitis (NSIP). The maternal grandfather had died of a life-long undiagnosed respiratory disorder [27]. The same abnormality has been described in other family members with ILD [28, 29]. NoGEE et al. [29] determined the presence of SP-C mutations 
in infants with neonatal respiratory distress, and found a mutation in 11 out of 34 patients evaluated [28, 29]. It is likely that the mutations may be sporadic or have autosomal dominant inheritance. Furthermore, a recent paper describing an extended family with familial ILD, which turned out to be associated with heterozygosity for a SP-C mutation, documented that presentation in adult life was with the histology of UIP, a form of ILD virtually unknown in children, whereas what was presumably exactly the same disease in children was diagnosed as cellular NSIP [30]. This illustrates the importance of a developmental perspective; the same disease may produce very different histological patterns at different ages. However, mutation analysis of SP-B and -C genes should increasingly be considered as part of the work up of ILD of unknown cause at any age, particularly if familial.

It is likely that further inherited surfactant protein problems will be described, given the complex processing of these molecules. A recent study of 21 infants with severe neonatal surfactant deficiency of unknown cause, with normal SP-B and -C gene sequences, revealed mutations in 16 infants in the ATP-binding cassette transporter A3 (ABCA3). Lung ultrastructure showed markedly abnormal lamellar bodies. ABCA3 is localised to lamellar bodies, suggesting an important role in surfactant metabolism [31]. It is likely that mutations in many other genes encoding for proteins important in surfactant metabolism will be implicated in ILD. Polymorphisms in genes important in surfactant metabolism, insufficiently severe to cause neonatal ILD, may yet be important in adult ILD when combined with an environmental insult. This hypothesis should be readily testable using the large tissue and DNA banks stored by many adult units.

Surfactant proteins are not the only novel paediatric issues. PIG was first described in seven infants who presented with tachypnoea, hypoxaemia and diffuse infiltrates with hyperinflation [3]. Lung biopsy showed interstitial expansion by spindle cells containing periodic-acid Schiff-positive, diastaselabile material consistent with glycogen. Five were treated with pulse corticosteroids, one with additional hydroxychloroquine; six of seven did well. The authors proposed that this was an abnormality in lung cytodifferentiation involving interstitial mesenchymal cells, because abundant glycogen is not normally found in pulmonary interstitial cells. Importantly, if glycogen is not carefully sought, PIG would be misdiagnosed as cellular NSIP. Are there adult PIGs mixed in with the ragbag of NSIP? Another ILD that has so far only been recognised in infants is NEHI [4]. Infants present with respiratory distress, and hyperinflation and ground glass opacities are found on HRCT. Lung biopsies look essentially normal, unless they are stained for bombesin, which demonstrates hyperplasia of the neuroendocrine cells and bodies. Should bombesin staining be part of the evaluation of clinical ILD with an apparently normal lung biopsy in adults? The relation of NEHI to adult idiopathic diffuse hyperplasia of pulmonary neuroendocrine cells is also under question [32].

ILD is, therefore, a very hot topic, with the study of neonatal disease in particular resulting in important lessons for physicians looking after ILD at all ages. In this context, the report of the ERS Task Force published in this issue of the European Respiratory Journal is particularly timely [33]. The distinguished members of the Task Force have performed a signal service by demonstrating that pan-European collaboration in this challenging field can be accomplished. They have reported 185 cases of paediatric ILD, the pathways for investigation, the treatment offered and the outcome; in addition, this is the largest series in the world literature. It has always been quite obvious that international collaboration will be essential if progress is to be made, and also that those with adult as well as paediatric expertise must collaborate.
To their credit, this is exactly what the Task Force has achieved, for the first time. However, as always, no sooner has one good study been performed then the spectators demand something better. It is accepted that the bedrock of diagnosis for the majority of paediatric ILD is the examination of lung tissue, usually a lung biopsy via mini-thoracotomy or videoassisted surgery. However, any biopsy is only as good as the pathologist who examines it. It follows that the way forward must be standardised processing of the biopsy, including preservation for electron microscopy, and freezing at $-70^{\circ} \mathrm{C}$; probably storing DNA on all children who are biopsied; and standardised staining and examination by specialist pathologists. Once diagnosis is truly assured, we can proceed to correlation of pathology with imaging, probably HRCT, possibly using the raised-volume, assisted-ventilation technique [34], to try in the future to reduce the number of invasive procedures that our children endure. Once diagnosis is secure, then we can establish cohorts of specific diagnostic entities to undertake proper therapeutic trials. Modern ILD treatment is not just "steroids for everything"; new cytokinebased therapies, such as interferon $\gamma-1 \mathrm{~b}$ for fibrosing alveolitis [35], GM-CSF for adult-onset PAP [16] and anti-tumour necrosis factor- $\alpha$ receptor blockers for sarcoidosis [36], herald a new era of treatment. However, modern powerful treatments will fall into disrepute unless they are targeted to the correct diagnostic categories; we owe it to the basic scientists to fire these magic bullets precisely and not at random.

How then do we take the work of the Task Force forward? This Europe-wide initiative needs to continue; national initiatives, like the British Paediatric Orphan Lung Disease (BPOLD), will be useful means of ensuring that data collection is as comprehensive as possible. The National Institutes of Health have funded a Rare Lung Diseases Consortium, and also awarded a conference grant to hold what was a very successful meeting on paediatric ILD in Cincinatti in March 2004. This resulted in the setting up of a Paediatric Interstitial Lung Disease Foundation by parents of affected children [37], and the establishment of working groups on pathology, radiology and other aspects of ILD.

I suggest we now need worldwide collaboration, ensuring diagnostic accuracy by standard protocols of investigation, and the sharing of images and biopsies between major centres round the world. With such collaboration, we could then assemble sufficiently large cohorts of patients to do proper therapeutic trials. If we make the mistake of regarding the excellent work of the Task Force as an end, not a beginning, we will continue in the dark ages of each centre having only a handful of children, and treating them by anecdote not evidence.

\section{References}

1. Coultas DB, Zumwalt RE, Black WC, Sobonya RE. The epidemiology of interstitial lung diseases. Am J Respir Crit Care Med 1994; 150: 967-972.

2. Dinwiddie R, Sharief N, Crawford O. Idiopathic interstitial pneumonitis in children: a national survey in the United Kingdom and Ireland. Pediatr Pulmonol 2002; 34: 23-29.

3. Canakis AM, Cutz E, Manson D, $\mathrm{O}^{\prime}$ Brodovich $\mathrm{H}$. Pulmonary interstitial glycogenosis: a new variant of neonatal interstitial lung disease. Am $J$ Respir Crit Care Med 2002; 165: 1557-1665.

4. Deterding RR, Fan LL, Morton R, Hay TC, Langston C. Persistent tachypnea of infancy (PTI)-a new entity. Pediatr Pulmonol 2001; S23: 72-73.

5. Barbato A, Panizzolo C, Cracco A, et al. Interstitial lung disease in children: a multicentre survey on diagnostic approach. Eur Respir J 2000; 16: 509-513. 
6. Langston C, Kida K, Reed M, Thurlbeck WM. Human lung growth in late gestation and in the neonate. Am Rev Respir Dis 1984; 129: 607-613.

7. Cordonnier C, Fleury-Feith J, Escudier E, Atassi K, Benaudin JF. Secondary alveolar proteinosis is a reversible cause of respiratory failure in leukemic patients. Am J Respir Crit Care Med 1994; 149: 788-794.

8. Ruben FL, Talamo TS. Secondary alveolar proteinosis occurring in two patients with acquired immune deficiency syndrome. Am J Med 1986; 80: 1187-1190.

9. Buechner HA, Ansari A. Acute silico-proteinosis: a new pathologic variant of acute silicosis in sandblasters, characterized by histologic features resembling alveolar proteinosis. Dis Chest 1969; 55: 274-278.

10. Garcia Rio F, Alvarez-Sala R, Caballero P, et al. Six cases of pulmonary alveolar proteinosis: presentation of unusual associations. Monaldi Arch Chest Dis 1995; 50: 12-15.

11. Dranoff G, Crawford AD, Sadelain M, et al. Involvement of granulocyte-macrophage colony-stimulating factor in pulmonary homeostasis. Science 1994; 264: 713-716.

12. Stanley E, Lieschke GJ, Sadelain M, et al. Involvement of granulocyte-macrophage colony-stimulating factor deficient mice show no major perturbation of hematopoiesis but develop a characteristic pulmonary pathology. Proc Natl Acad Sci USA 1994; 91: 5592-5596.

13. Kitamura $\mathrm{T}$, Tanaka N, Watanabe $\mathrm{J}$, et al. Idiopathic pulmonary alveolar proteinosis as an autoimmune disease with neutralizing antibody against granulocyte/macrophage colony stimulating factor. J Exp Med 1999; 190: 875-880.

14. Bonfield TL, Russell D, Burgess S, et al. Autoantibodies against granulocyte macrophage colony-stimulating factor are diagnostic for pulmonary alveolar proteinosis. $\mathrm{Am}$ J Respir Cell Mol Biol 2002; 27: 481-486.

15. Dirksen U, Nishinakamura R, Groneck P, et al. Human pulmonary alveolar proteinosis associated with a defect in GM-CSF/IL-3/IL-5 receptor common beta chain expression. J Clin Invest 1997; 100: 2211-2217.

16. Bonfield TL, Farver CF, Barna BP, et al. Peroxisome proliferator-activated receptor- $\gamma$ is deficient in alveolar macrophages from patients with alveolar proteinosis. Am J Respir Cell Mol Biol 2003; 29: 677-682.

17. Brasch F, Johnen G, Winn-Brasch A, et al. Sutfactant protein B in type 11 pneumocytes and intra-alveolar surfactant forms of human lungs. Am J Respir Cell Mol Biol 2004; 30: 449-458.

18. Somaschini M, Wert S, Mangili G, Colombo A, Nogee L. Hereditary surfactant protein B deficiency resulting from a novel mutation. Intensive Care Med 2000; 26: 97-100.

19. Tredano M, van Elburg RM, Kaspers AG, et al. Compound SFTPB 1549C --> GAA (121ins2) and 457delC heterozygosity in severe congenital lung disease and surfactant protein B (SP-B) deficiency. Hum Mutat 1999; 14: 502-509.

20. Nogee LM, Wert SE, Profitt SA, Hull WM, Whitsett JA. Allelic heterogeneity in hereditary surfactant protein B (SP-B) deficiency. Am J Respir Crit Care Med 2000; 161: 973-981.

21. Cole FS, Hamvas A, Rubinstein P, et al. Population-based estimates of surfactant protein B deficiency. Pediatrics 2000; 105: 538-541.

22. Beers MF, Hamvas A, Moxley MA, et al. Pulmonary surfactant metabolism in infants lacking surfactant protein B. Am J Respir Cell Mol Biol 2000; 22: 380-391.

23. Klein JM, Thompson MW, Snyder JM, et al. Transient surfactant protein B deficiency in a term infant with severe respiratory failure. J Pediatr 1998; 132: 244-248.

24. Vorbroker DK, Profitt SA, Nogee LM, Whitsett JA. Aberrant processing of surfactant protein $\mathrm{C}$ in hereditary SP-B deficiency. Am J Physiol 1995; 268: L647-L656.

25. Hamvas A, Nogee LM, Mallory GB Jr, et al. Lung transplantation for treatment of infants with surfactant protein B deficiency. J Pediatr 1997; 130: 231-239.

26. Dunbar III AE, Wert SE, Ikegami M, et al. Prolonged survival in hereditary surfactant protein B (SP-B) deficiency associated with a novel splicing mutation. Pediatr Res 2000; 48: 275-282.

27. Nogee LM, Dunbar III AE, Wert SE, et al. A mutation in the surfactant protein $\mathrm{C}$ gene associated with familial interstitial lung disease. $N$ Engl J Med 2001; 344: 573-579.

28. Amin RS, Wert SE, Baughman RP, et al. Surfactant protein deficiency in familial interstitial lung disease. J Pediatr 2001; 139: 85-92.

29. Nogee LM, Dunbar III AE, Wert SE, et al. Mutations in the surfactant protein $\mathrm{C}$ gene associated with interstitial lung disease. Chest 2002; 121: 20S-21S.

30. Thomas AQ, Lane K, Phillips J 3rd, et al. Heterozygosity for surfactant protein $\mathrm{C}$ gene mutation associated with usual interstitial pneumonitis and cellular nonspecific interstitial pneumonitis in one kindred. Am J Respir Crit Care Med 2002; 165: 1322-1328.

31. Shulenin S, Nogee LM, Annilo T, Wert SE, Whitsett JA, Dean M. $A B C A 3$ gene mutations in newborns with fatal surfactant deficiency. N Engl J Med 2004; 350: 12961303.

32. Aguayo SM, Miller YE, Waldron JA, et al. Brief Report: idiopathic diffuse hyperplasia of pulmonary neuroendocrine cells and airways disease. $N$ Engl J Med 1992; 327: 12851288.

33. Clement A, and committee members. Task force on chronic interstitial lung disease in immunocompetent children. Eur Respir J 2004; 24: 686-697.

34. Long FR, Castile RG. Technique and clinical applications of full-inflation and end-exhalation controlled-ventilation chest CT in infants and young children. Pediatr Radiol 2001; 31: 413-422.

35. Raghu G, Brown KK, Bradford WZ, et al. A placebocontrolled trial of interferon gamma- $1 \mathrm{~b}$ in patients with idiopathic pulmonary fibrosis. $N$ Engl J Med 2004; 350: 125-133.

36. Roberts SD, Wilkes DS, Burgett RA, Knos KS. Refractory sarcoidosis responding to infliximab. Chest 2003; 124: 2028-2031.

37. Carter B. www.PLDFamilyNetwork.org. Date last updated: 22 July 2004. 